\title{
Nonlinear analysis of water-soil-barrage floor interaction
}

\author{
Abdul-Hassan Al-Shukur ${ }^{1}$, Atheer Zaki Al-Qaisi ${ }^{2, *}$, Ayaat Majid Al-Rammahi ${ }^{1}$ \\ ${ }^{1}$ College of Engineering, University of Babylon, Babylon, Iraq \\ ${ }^{2}$ Al-Mussaib Technical College, Al-Furat Al-Awsat Technical University, Babylon, Iraq
}

\begin{abstract}
Fluid - Structure Interaction (FSI) and Soil-Structure Interaction (SSI) are mostly considered in the non-linear analysis of water-soil-barrage floor interaction. A three dimensional (3D) - section of a barrage is selected and modelled via ANSY 15.0. The ogge barrage floor shape has been taken as a case study of analysis. The non-linear analysis of the structure model is developed through selecting suitable available elements in ANSYS which are related to the case under study and is compared with linear analysis. The results of the analysis are obtained by suggesting different characteristics of concrete, soil, and rock materials as a parametric study. Both closed barrage and in operation are the cases have been considered in analysis. It is concluded from this study that ANSYS/APDL is adequate tool to simulate and analysis the problem that need sufficient experiences to select suitable available elements to get the acceptable results. It is also concluded that the deformation in barrage floor has little difference by $(6 \%)$ in linear and non-linear analysis in case of no operation. While this deformation in non-linear analysis with operation condition is less by $(13 \%)$ than of no operation case. The non-linear deformation of barrage floor is more effective by change of density of barrage concrete itself, modulus of elasticity and yield stress of both soil and rock foundation materials, while no sensitive effect of change of Poisson's ratio on the deformation. The maximum seepage flow at exit point downstream barrage floor with upstream and downstream piles is lesser by $(67.40 \%)$ than without pile. In the view of stability, it is concluded that the barrage floor is already safe in exist gradient and piping problems with or without piles.
\end{abstract}

\section{Introduction}

Barrage is that type of hydraulic structures which is relatively low-level dams and constructed across a river for the purpose of rising water

As a non-gravity structure, the upstream concrete barrage floor is relatively thin (i.e. it is stable with small load), while the downstream concrete floor is built so as to contain the hydraulic jump [1].

Most hydraulic structures behave as Soil-Structure Interaction (SSI) or Fluid-Structure Interaction (FSI) or both SFSI $[2,3,4]$. The barrage floor is in contact with water and soil. So it behaves as a fluid-structure and soil-structure interaction problems under effect of different types of loads.

Finite element modelling and analysis are carried out to give the behaviour of barrage floor resting on homogeneous soil condition considering soil-raftstructure system [5]. The non-linear SSI analyses with advances in computer analysis capabilities can ensure cost - effective of an entire soil - foundation superstructure system [6].

The scope of recent researches is to present a nonlinear analysis of water-soil-barrage floor interaction. In present study, the stresses, displacements, uplift pressure distribution, hydraulic gradient, and percentage of seepage under barrage are analysed and the results of these analysis are presented in the forms of tables and figures.

\section{Numerical modelling of the problem}

The ANSYS software is used for finite element modelling. To achieve this purpose, a case study from [7] has been taken to be simulated.

An ogee shape of a typical barrage section (bays 34), have been selected for this study as shown in Fig. 1(a and $b$ ).

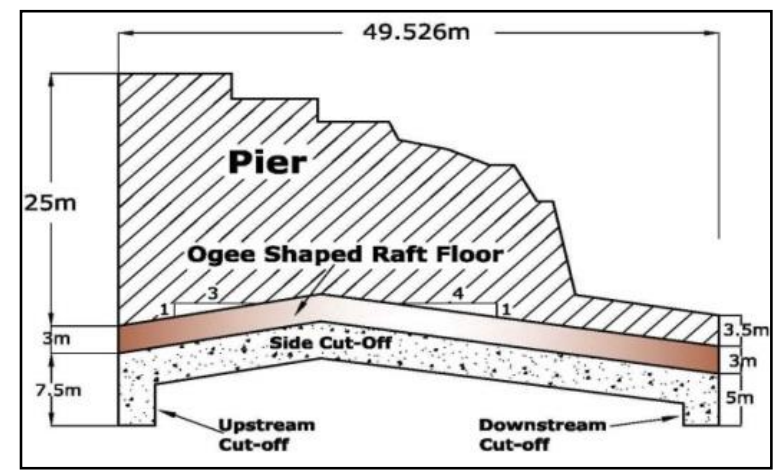

Fig. 1-a. Side view of barrage [7]. 


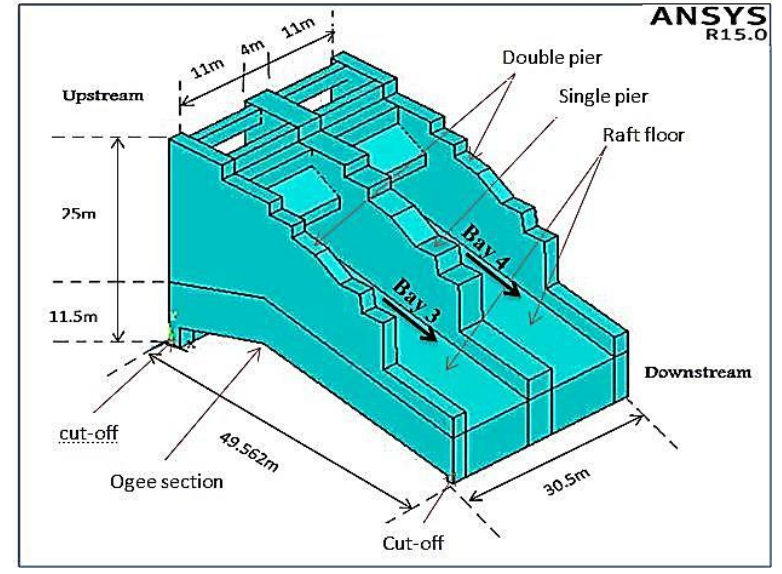

Fig. 1-b. 3D section of barrage.

Fig.1. Barrage section; a. Side view, b. 3D section [7].

A 3D-shape with 8-Node SOLID 185 element (homogenous structural solid), shown in Fig. (2) which is available in ANSYS 15.0, is a suitable element used for modelling of soil and rock foundation. Such element has three degrees of freedom at each node: translations in the nodal $\mathrm{x}, \mathrm{y}$, and $\mathrm{z}$ directions. The element has plasticity, hyper elasticity, stress stiffening, creep, large deflection, and large strain capabilities. It also has mixed formulation capability for simulating deformations of nearly incompressible elastoplastic materials, and fully incompressible hyper elastic materials [8].
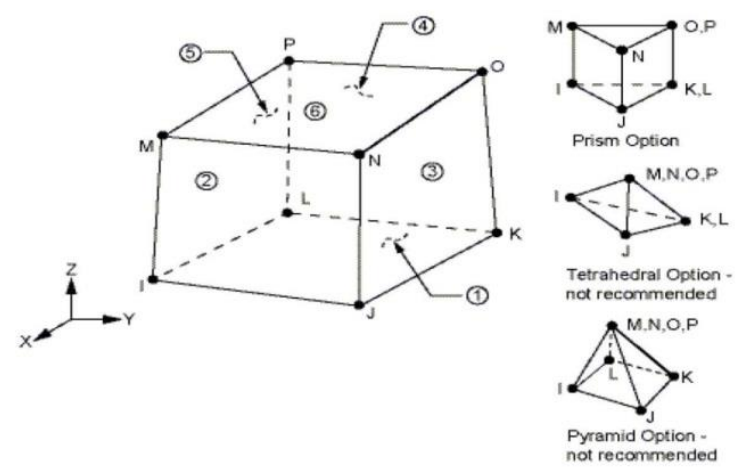

Fig. 2. SOLID 185 element geometry [8].

The Extended Drucker -Prager (EDP) material of soil is modeled to represent the non-linear behavior of the soil with structure. There are several topics to define the EDP material model. However, EDP yield criteria and linear plastic flow potential function forms are selected to model the soil. The EDP linear yield criteria form is:

$$
f\left(\sigma, \sigma_{y}\right)=\sigma_{e}+\alpha \frac{1}{3} \operatorname{tr}(\sigma)-\sigma_{y}=0
$$

Where: $\boldsymbol{\alpha}$ and $\boldsymbol{\sigma}_{\boldsymbol{y}}$ are pressure sensitivity and uniaxial yield stress, respectively and depend on both shear strength parameters of soil ( $C$ and $\phi$ )which should be defined as constants $\left(\boldsymbol{C}_{\mathbf{1}}\right.$ and $\left.\boldsymbol{C}_{\mathbf{2}}\right)$ in ANSYS/APDL.

In other hand, the linear form of the plastic flow potential is:

$$
Q\left(\sigma, \sigma_{y}\right)=\sigma_{e}+\bar{\alpha} \frac{1}{3} \operatorname{tr}(\sigma)
$$

Where: $\overline{\boldsymbol{\alpha}}$ is the flow potential pressure sensitivity.
The other soil parameters that also should be defined are modulus of elasticity $\mathbf{E}_{\boldsymbol{s}}$, Poisson's ratio $\boldsymbol{\vartheta}_{\mathbf{s}}$, and density $\boldsymbol{\rho}_{\mathbf{s}}$. Tables (1 and 2 ) give values of the soil and rock parameters.

Table 1. Soil domain properties [7, 9].

\begin{tabular}{|l|c|c|}
\hline \multicolumn{1}{|c|}{ Material Properties } & $\begin{array}{c}\text { Symbol in } \\
\text { ANSYS }\end{array}$ & $\begin{array}{c}\text { Corresponding } \\
\text { Values }\end{array}$ \\
\hline Nonlinear properties [9] & \multicolumn{3}{|c|}{} \\
\hline Pressure sensitivity, $\alpha$ & $\mathrm{C}_{1}$ & 2.252 \\
\hline Uniaxial yield stress, $\sigma_{\mathrm{y}}$ & $\mathrm{C}_{2}$ & $23.40 \mathrm{KPa}$ \\
\hline Flow potential, Q & LFPOT & 0.59 \\
\hline Linear properties [7] & $\mathrm{EX}$ & $1 \times 10^{5} \mathrm{KPa}$ \\
\hline Modulus of elasticity, $\mathrm{E}_{\mathrm{s}}$ & & 0.3 \\
\hline Poisson's ratio, $\vartheta_{\mathrm{s}}$ & $\mathrm{NUXY}$ & \\
\hline Density, $\boldsymbol{\rho}_{\mathrm{s}}$ & $\mathrm{DENS}$ & $\mathbf{2 0 0 0} \mathbf{~ k g} / \mathbf{m}^{\mathbf{3}}$ \\
& & \\
\hline
\end{tabular}

\begin{tabular}{|c|c|c|}
\hline Material Properties & $\begin{array}{l}\text { Symbol in } \\
\text { ANSYS }\end{array}$ & $\begin{array}{c}\text { Corresponding } \\
\text { Values }\end{array}$ \\
\hline \multicolumn{3}{|l|}{ Nonlinear properties[9] } \\
\hline Pressure sensitivity, $\alpha$ & $\mathrm{C}_{1}$ & 0.875 \\
\hline Uniaxial yield stress, $\sigma_{\mathrm{y}}$ & $\mathrm{C}_{2}$ & $12000 \mathrm{KPa}$ \\
\hline Flow potential, Q & LFPOT & 0.7 \\
\hline \multicolumn{3}{|l|}{ Linear properties[7] } \\
\hline Modulus of elasticity, $E_{r}$ & $E X$ & $1 * 10^{7} \mathrm{KPa}$ \\
\hline Poisson's ratio, $\vartheta_{\mathrm{r}}$ & $N U X Y$ & 0.25 \\
\hline Density, $\boldsymbol{\rho}_{\mathbf{r}}$ & DENS & $2600 \mathrm{~kg} / \mathrm{m}^{3}$ \\
\hline
\end{tabular}

Table 2. Rock domain properties [7, 9].

About the barrage there are two types of floors, the first being called the gravity type and the second as the raft type [10]. The raft type is recommended and discussed in this study. This type of floor is constructed as reinforced concrete structures. A 3D-8-node SOLID 65 element is a suitable available one via ANSYS to model this type of barrage floor. The description geometry of this element is shown in Fig 3. The solid is capable of cracking in tension and crushing in compression. This element is used for the $3 \mathrm{D}$ modelling of solids with or without reinforcing bars (rebar). The element is defined by eight nodes having three degrees of freedom at each node: translations in the nodal $x, y$, and $\mathrm{z}$ directions. This element permits to model the concrete as a linear behavior concrete material as well as a non-linear behavior [8].

In other hand, Solid 187 element is also selected to simulate the barrage itself. It is a higher order $3 \mathrm{D}, 10$ node element having three degrees of freedom at each 
node: translations in the nodal $\mathrm{x}, \mathrm{y}$, and $\mathrm{z}$ directions as shown in Fig.4. The element has plasticity, hyperelasticity, creep, stress stiffening, large deflection, and large strain capabilities. It also has mixed formulation capability for simulating deformations of nearly incompressible elastoplastic materials, and fully incompressible hyperelastic materials.

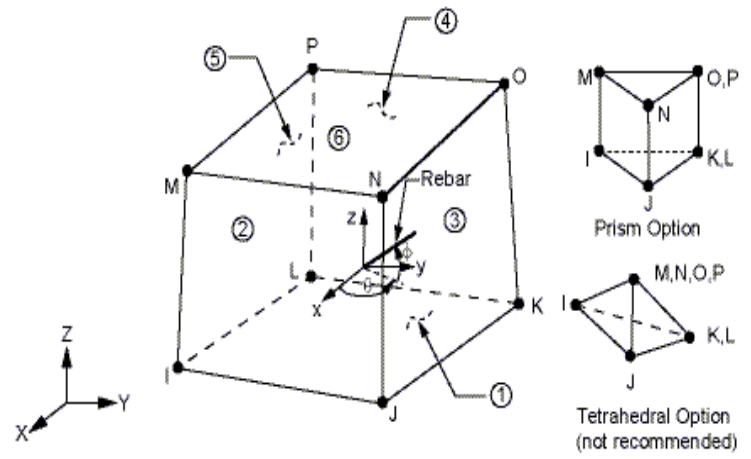

Fig. 3. SOLID 65 element geometry [8].

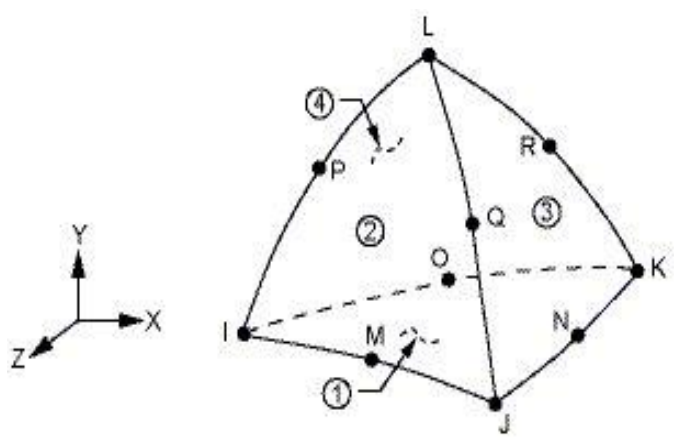

Fig. 4. SOLID 187 element geometry [8].

In this study, the behaviour of non-linearity of concrete is considered. In this case, the concrete is capable of plasticity, creep, cracking and crushing [11]. In other hand, the criterion for failure of concrete due to a multiaxial stress state can be expressed in the form [12]:

$$
\frac{\mathbf{F}}{\mathbf{f}_{\mathbf{c}}}-\mathbf{S} \geq \mathbf{0}
$$

Where: $\mathbf{F}=$ a function of the principlal stress $\left(\sigma_{\mathrm{xp}}, \sigma_{\mathrm{yp}}, \sigma_{\mathrm{zp}}\right)$

$\mathbf{S}=$ failure surfac expressed in terms of principal stresses and five input parameters $\mathbf{f}_{\mathbf{t}}, \mathbf{f}_{\mathbf{c b}}, \mathbf{f}_{\mathbf{1}}$, and $\mathbf{f}_{\mathbf{2}}$ defind in Table (3),

$\mathbf{f}_{\mathbf{c}}=$ uniaxial crushing strength, and

$\boldsymbol{\sigma}_{x \boldsymbol{p}}, \boldsymbol{\sigma}_{\boldsymbol{y} \boldsymbol{p}}, \boldsymbol{\sigma}_{z \boldsymbol{p}}=$ principal stresses in principlal directions.

If Eq. (2) is satisfied, the material will crack or crush. A total of five input strength parameters are presented in Table (3). So, the material that is used in barrage floor is a mass concrete and the specifications of concrete material that should be defined in ANSYS/APDL are density $\boldsymbol{\rho}_{\mathbf{c}}$, modulus of elasticity $\mathbf{E}_{\mathbf{c}}$, and Poisson's ratio $\boldsymbol{\vartheta}_{\mathbf{c}}$. The specifications of C35 grade concrete are as given in Table (3).

Table 3. Mass concrete properties [7].

\begin{tabular}{|c|c|c|}
\hline Material Properties & $\begin{array}{l}\text { Symbol in } \\
\text { ANSYS }\end{array}$ & $\begin{array}{c}\text { Corresponding } \\
\text { Values }\end{array}$ \\
\hline \multicolumn{3}{|l|}{ Pier/Abutment [7] } \\
\hline Modulus of elasticity, $E_{c}$ & EX & $25 \mathrm{Gpa}$ \\
\hline Poisson's ratio, $\vartheta_{c}$ & NUXY & 0.15 \\
\hline Density, $\rho_{c}$ & DENS & $2500 \mathrm{~kg} / \mathrm{m}^{3}$ \\
\hline \multicolumn{3}{|l|}{ Raft Floor [7] } \\
\hline Modulus of elasticity, $\mathrm{E}_{\mathrm{c}}$ & EX & 25 Gpa \\
\hline Poisson's ratio, $\vartheta_{\mathrm{c}}$ & NUXY & 0.18 \\
\hline Density, $\rho_{c}$ & DENS & $2500 \mathrm{~kg} / \mathrm{m}^{3}$ \\
\hline \multicolumn{3}{|c|}{ Nonlinear properties for both pier and floor } \\
\hline $\begin{array}{l}\text { Shear transfer coefficients } \\
\text { for an open crack. }\end{array}$ & $\overline{C_{1}}$ & $0.3^{* *}$ \\
\hline $\begin{array}{l}\text { Shear transfer coefficients } \\
\text { for a closed crack. }\end{array}$ & $\mathrm{C}_{2}$ & $1 * *$ \\
\hline $\begin{array}{l}\text { Ultimate uniaxial tensile } \\
\text { strength, } \mathrm{f}_{\mathrm{t}}\end{array}$ & $\mathrm{C}_{3}$ & $1.5 \mathrm{Mpa}^{*}$ \\
\hline $\begin{array}{l}\text { Ultimate uniaxial } \\
\text { compressive strength, } \mathbf{f}_{\mathbf{c}}\end{array}$ & $\mathrm{C}_{4}$ & 30 Мра* \\
\hline
\end{tabular}

* From [13].

** From [14].

The main function of a barrage is to work as a low dam. The retained water is on the upstream and downstream barrage is considered in this study. FSI involves as the pressure load on the barrage floor. FLUID 30 Element is by ANSYS 15.0 for modelling the fluid medium and the interface in fluid/structure interaction problems. It has 8-corner nodes with four degrees of freedom per node: translations in the nodal $\mathrm{x}, \mathrm{y}$ and $\mathrm{z}$ directions and pressure as shown in Fig. (5). The translations, however, are applicable only at nodes that are on the interface. Typical applications include sound wave propagation and submerged structure dynamics. The governing equation for acoustics, namely the 3-D wave equation, has been discretized taking into account the coupling of acoustic pressure and structural motion at the interface. When there is no structural motion, the element is also applicable to static, modal and reduced harmonic response analyses. This element needs to be defined by some parameters, namely, a reference pressure, and the isotropic material properties. The speed of sound $\left(\sqrt{\mathrm{K} / \rho_{\mathrm{w}}}\right)$ in the fluid is input by SONC where $\mathrm{K}$ is the bulk modulus of the fluid (Force/Area) and $\rho_{\mathrm{w}}$ is the mean fluid density (Mass/Volume) (input as DENS). The dissipative effect due to fluid viscosity is also included and input as (MP, VISC). All these materials of water domain could be given in Table (4). 


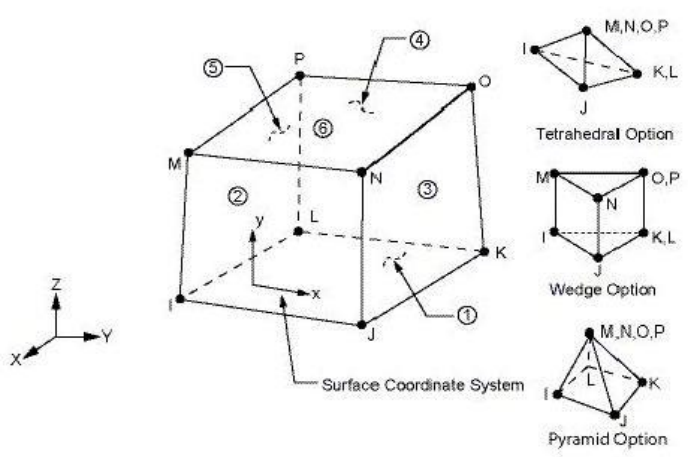

Fig.5. FLUID 30 element geometry [8].

Table 4. Fluid (water) domain properties [4].

\begin{tabular}{|l|c|c|}
\hline Material Properties & $\begin{array}{c}\text { Symbol in } \\
\text { ANSYS }\end{array}$ & $\begin{array}{c}\text { Corresponding } \\
\text { Values }\end{array}$ \\
\hline $\begin{array}{l}\text { Bulk modulus of the } \\
\text { fluid, } K_{w}\end{array}$ & $E X$ & $2.02 \mathrm{Gpa}$ \\
\hline $\begin{array}{l}\text { Reference } \\
\text { pressure, } P_{w}\end{array}$ & PREF & $20 \times 10^{-6} \mathrm{~Pa}$ \\
\hline Poisson's ratio, $\vartheta_{\mathrm{w}}$ & NUXY & 0.2 \\
\hline Sonic velocity, $V_{w}$ & $S O N C$ & $1440 \mathrm{~m} / \mathrm{s}$ \\
\hline Density, $\rho_{w}$ & $D E N S$ & $1000 \mathrm{~kg} / \mathrm{m}^{3}$ \\
\hline Viscosity, $\boldsymbol{\mu}_{w}$ & $V I S C$ & $1.0 \times 10^{-3} \mathrm{~Pa} . \mathrm{S}$ \\
\hline
\end{tabular}

To study the contact between two bodies, the surface of one body is conventionally taken as a contact surface and the surface of the other body as a target surface. The "contact-target" pair concept has been widely used in finite element simulations. For rigid-flexible contact, the contact surface is associated with the deformable body; and the target surface must be the rigid surface. For flexible-flexible contact, both contact and target surfaces are associated with deformable bodies. The contact and target surfaces constitute a "Contact Pair".

The interface elements that modeled the interaction among water and soil with barrage floor are CONTA 174 and TARGE170. CONTA174 is used to represent contact and sliding between 3D "target" surfaces (TARGE170) and a deformable surface, defined by this element as shown in Fig. (6). Contact occurs when the element surface penetrates one of the target segment elements (TARGE170) on a specified target surface. Coulomb and shear stress friction is allowed. This element also allows separation of bonded contact to simulate interface delamination.

TARGE170 is used to represent various 3D "target" surfaces for the associated contact element (CONTA 173) as shown in Fig.(7). The contact elements themselves overlay the solid, shell, or line elements describing the boundary of a deformable body and are potentially in contact with the target surface, defined by TARGE170. This target surface is discretized by a set of target segment elements (TARGE170) and is paired with its associated contact surface via a shared real constant set. The translational or rotational displacement, temperature, voltage, and magnetic potential, forces, and moments can be imposed on the target segment element on target elements. For rigid target surfaces, these elements can easily model complex target shapes. For flexible targets, these elements will overlay the solid, shell, or line elements describing the boundary of the deformable target body.

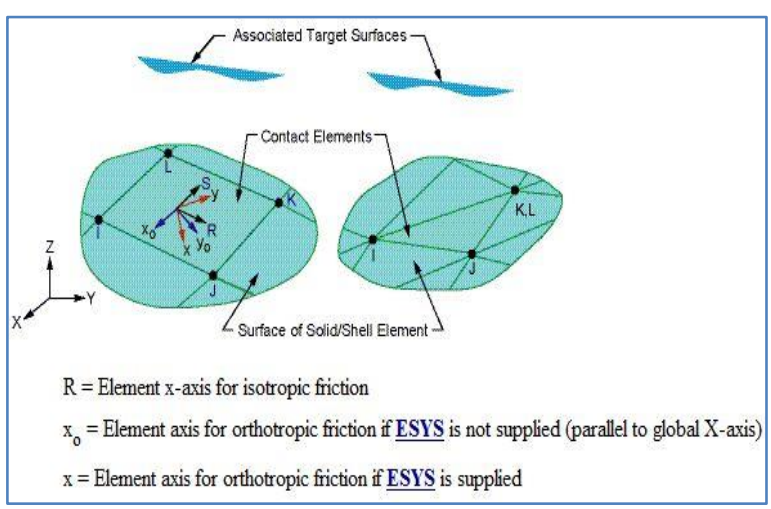

Fig. 6. CONTA 173 element geometry [8].

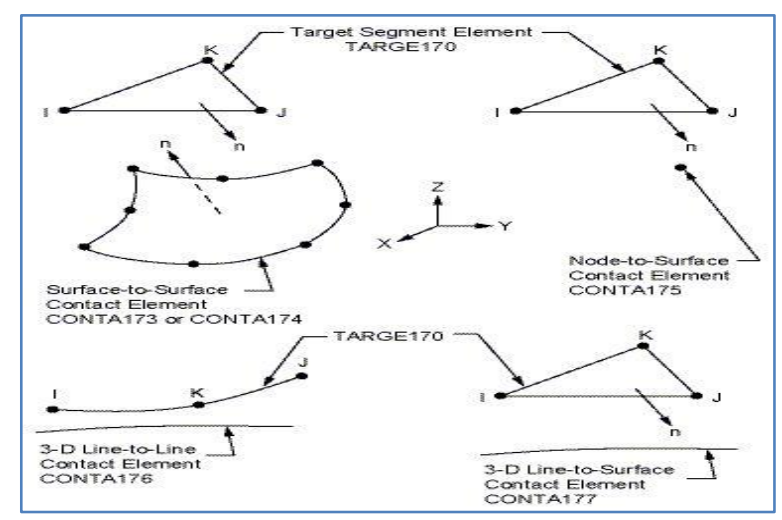

Fig.7. TARGE 170 element geometry [8].

The boundary conditions in this model are: the depth of the soil and rock media considered is $80 \mathrm{~m}$ from the crest level, the extent of the surrounding soil and rock is up to $35 \mathrm{~m}$ on both sides of the transverse section of the raft and $50 \mathrm{~m}$ on both in upstream and downstream side equivalent to the length of the raft floor along the flow has been considered [7].

The boundary condition imposed on the finite element models consist of restraining the limiting boundary of the foundation soil and rock in such manner that displacement normal to the boundary surface are restrained i.e. the base of the foundation media at the depth of $80 \mathrm{~m}$ is restrained against vertical displacement and at the ends along and across the direction of flow, foundation media is restrained against the horizontal displacement.

The weight of barrage body itself is applied on the foundation as a distributed load $\left(\mathrm{kN} / \mathrm{m}^{2}\right)$ by using (SF) command. The self-weight of the soil and rock media has not been considered as it has been assumed that 
entire soil and rock media is already settled by its own weight [7]. The water imposed behind barrage is considered as a pressure on the surface of a barrage floor. So it was represented also by (SF) command. In ANSYS 15.0, the fluid-structure interface (FSI) may be automatically flagged if acoustic elements are adjacent to solid structural elements. However, the FSI is flagged as a surface load (SF) on the interface of water-barrage and water - soil by defining fsi $=1$. The complex impedance value can be used to include damping that may be present at a structural boundary with a sound absorption lining. These impedance boundary conditions may also be applied to a flagged FSI interface. A zero value of IMPD removes the damping calculation. The displacement degrees of freedom (UX, UY and UZ) at the element nodes not on the interface should be set to zero to avoid zero-pivot warning messages if the coupled acoustic elements are used $(\operatorname{KEYOPT}(2)=1)$.

\section{Results analysis and discussion}

\subsection{Linear analysis}

According to linear materials properties given in Tables 1, 2, and 3, the barrage section shown in Fig. (1) is modelled with different structure elements that available in ANSYS. This model is simulated for static linear analysis at empty condition by using 8-nodes Solid 65 and 185 elements additionally of 10-nodes Solid 187 element to make some indication about behaviour the structure by using different mechanism of finite element. The deformation in y-direction (Uy) of barrage floor with distance at ogee section is compared with the results of element given in [7]; as shown in Fig. 8. The results shown in Fig. 8 show the convergence in results between current study and [7] with using Solid 65 and 185 elements, but give some different results when Solid 187 element has been used and this is because of the different geometry of this element from other and this will give some different behaviour of finite element itself.

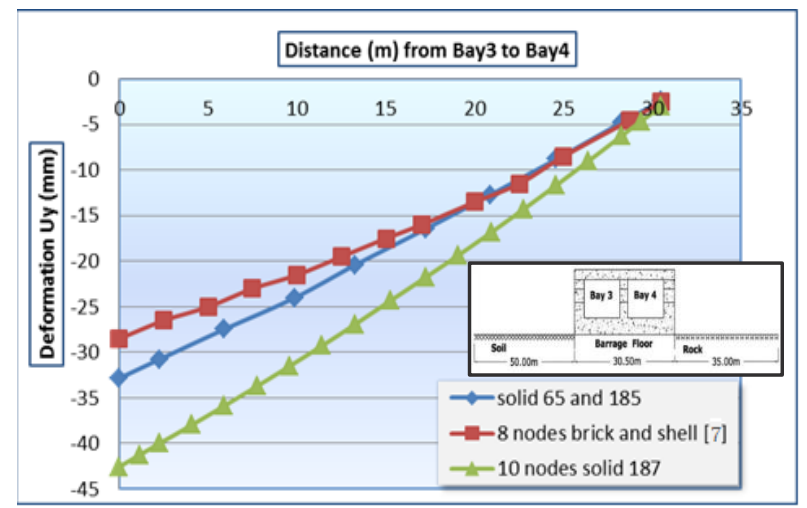

Fig. 8. Deformation of barrage by using different elements.

\subsection{Nonlinear analysis}

To make a comparison between linear and non-linear behaviours of barrage floor, the same section shown in
Fig. 1 and according to the nonlinear as well as to linear properties given in Tables 1, 2, and 3, the nonlinear analyses in non-operation condition by using solid 65 and solid 185 is performed and the results of deformation are shown in Fig. 9.

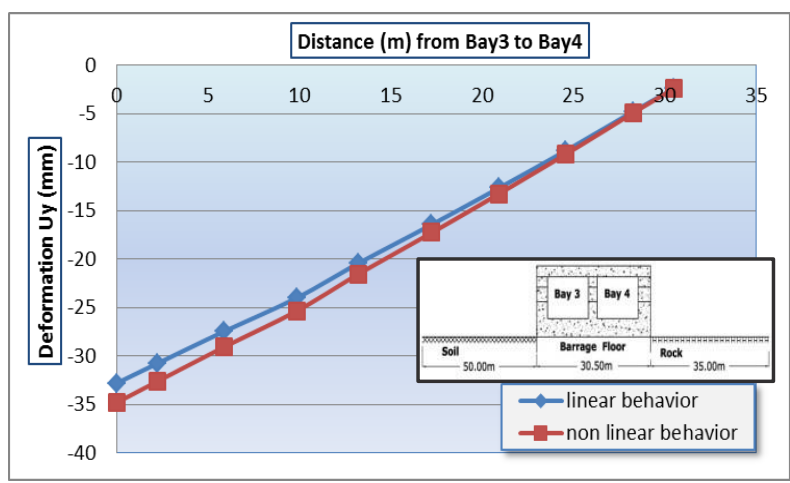

Fig. 9. Deformation of barrage by linear and nonlinear analysis at ogee section in non-operation condition.

It is shown from Fig. 9 that the deformation of barrage floor in both linear and nonlinear analyses give close results, where the difference is $6.12 \%$ only at the soil side of foundation. This is due to that in fact the design of hydraulic structures is depends on the working stress principle and taken as an uncracked section.

In addition to deformation; the stress at $\mathrm{x}, \mathrm{y}, \mathrm{z}$ directions in model is studded and shown in Fig. 10 ( a, $\mathrm{b}$, and $\mathrm{c}$ ).

Fig. $10(a, b$, and $c)$ indicates that the stress at $y$ direction is higher than other directions followed by $\mathrm{z}$ direction. This is due to interaction between soil and barrage floor and the displacement in y-direction. It is noticeable that a structure in contact with rock behaves as a rigid structure than in a flexible state. Therefore, the critical stress is shown at rock side of the modelled section than in the soil side of barrage (modulus elasticity of rock is greater by 100 times than that of soil (Tables 1 and 2)).

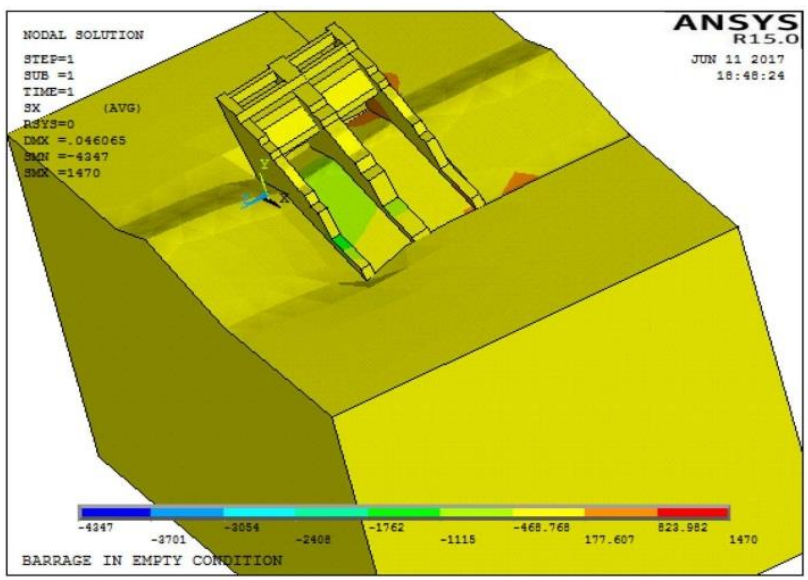

Fig. 10- a. Stress distribution in $\mathrm{x}$-direction. 


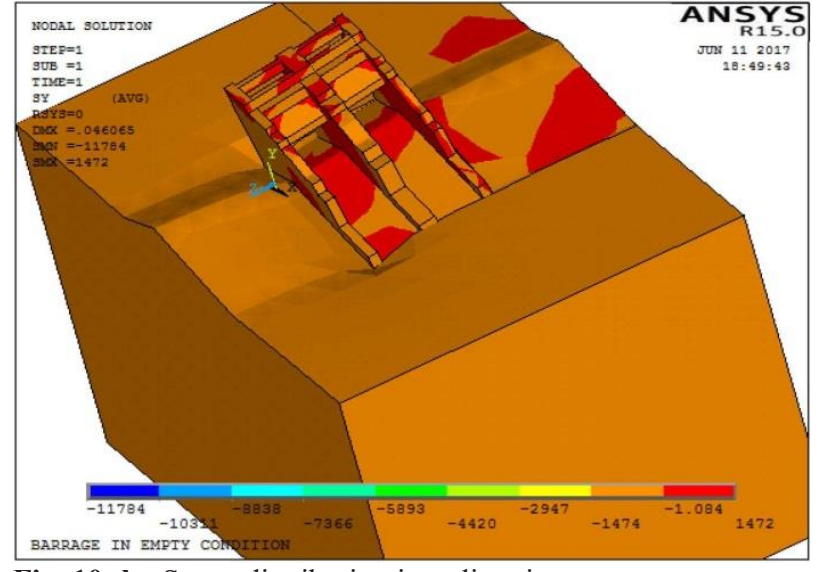

Fig. 10- b. Stress distribution in y-direction.

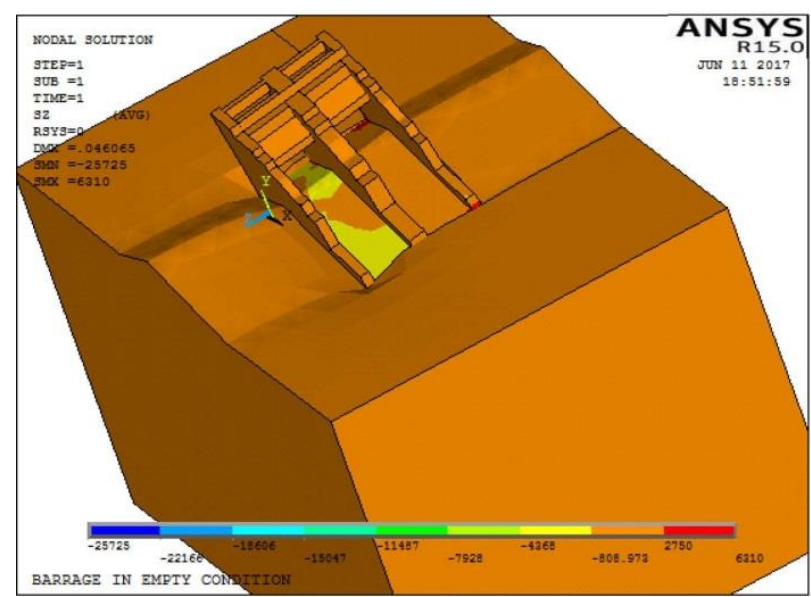

Fig. 10- c. Stress distribution in z-direction.

Fig. 10. Stress distribution in the considered barrage section; a. in $\mathrm{x}$-direction, $\mathrm{b}$. in $\mathrm{y}$-direction, c. in $\mathrm{z}$-direction.

Also, steady flow condition of barrage in nonlinear analysis is simulated by assuming $\mathrm{HFL}=8 \mathrm{~m}$ at upstream and $4 \mathrm{~m}$ at downstream which is suitable to the height of barrage at upstream and downstream conditions to compare with non-operation condition, as shown in Fig. 11.

The operation condition gives result slightly lower than the non-operation condition due to the presence of uplift pressure as shown in Fig. 12. This is happened as a result of balanced forces system equilibrium with the gravity load in the case of flow condition.

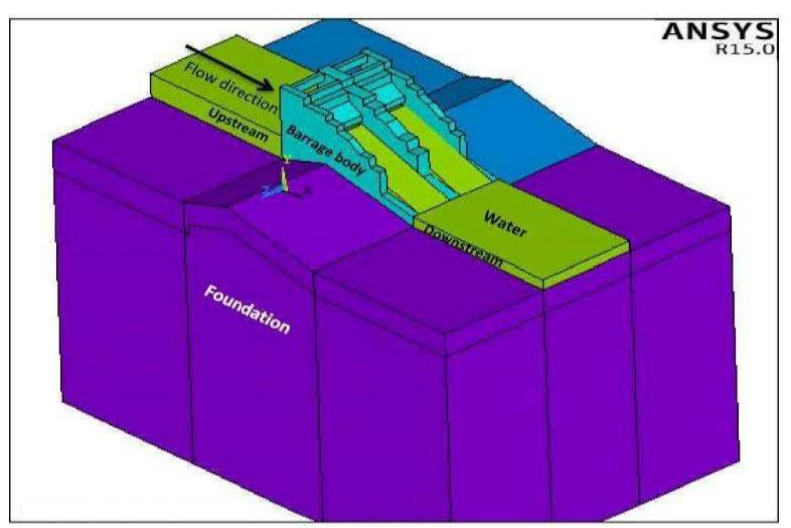

Fig.11. Operation condition model.

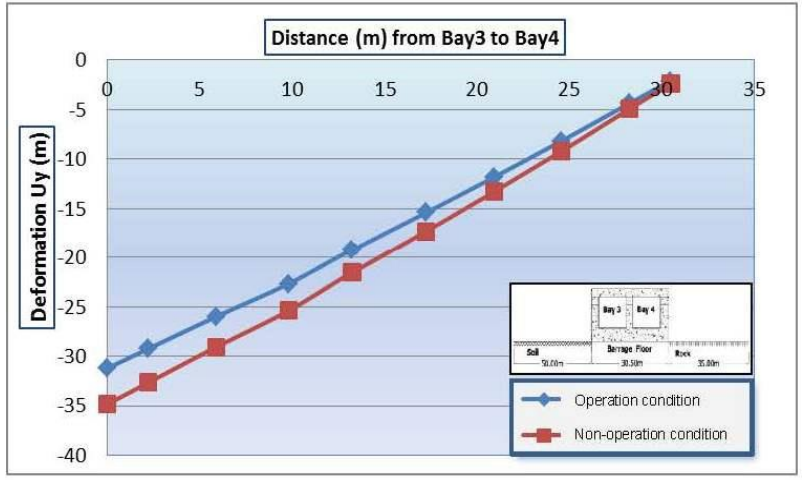

Fig. 12. Deformation of barrage with distance in operation and non- operation conditions at ogee section.

\subsection{Some effective parameters}

The properties of materials such as density $\rho$, modulus of elasticity E, Poisson's ratio $\vartheta$, and yield stress $\sigma_{\mathrm{y}}$ are selected as the effective parameters to give an indication on the behaviours of related structures at empty nonlinear condition for ogee section. The range of these properties are given in [15] as follows:

a- Density for barrage body $\left(\rho_{c}\right)$, soil foundation $\left(\rho_{s}\right)$, and rock foundation $\left(\rho_{\mathrm{r}}\right)$; as shown in Fig. (13- a, b, and $\mathrm{c}$ ). The selected values of these parameters depend on the principle of light to heavy structures.

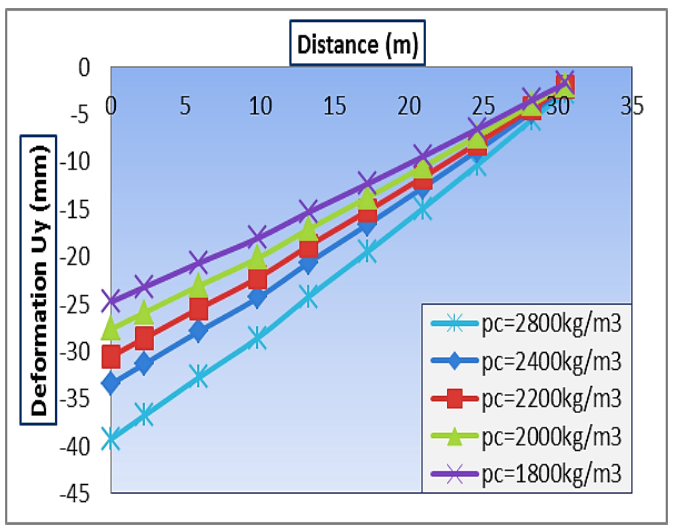

Fig. 13-a. Effect of density of barrage body on deformation.

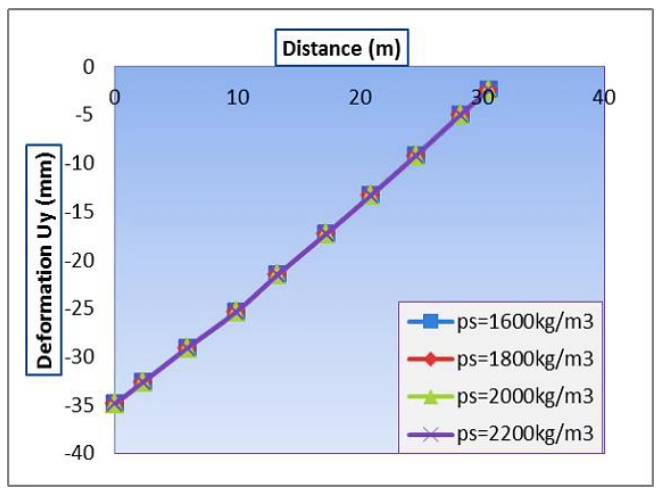

Fig. 13-b. Effect of density of soil foundation on deformation. 


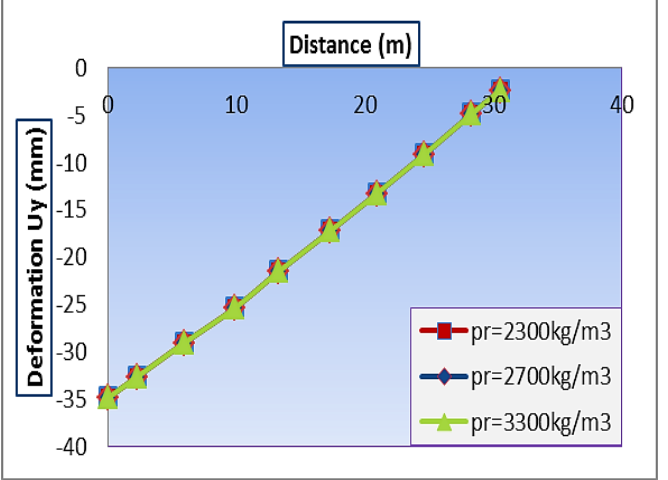

Fig. 13-c. Effect of density of rock foundation on deformation.

Fig. 13. Effect of density on deformation; a. barrage body, b. soil foundation, c. rock foundation.

b- Modulus of elasticity for barrage body (Ec), soil foundation (Es), and rock foundation (Er); as shown in Figures (14- a, b, and c).

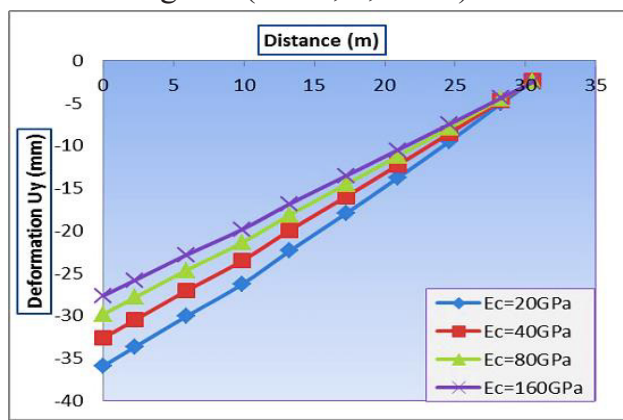

Fig. 14-a. Effect of modulus of elasticity of barrage body on deformation.

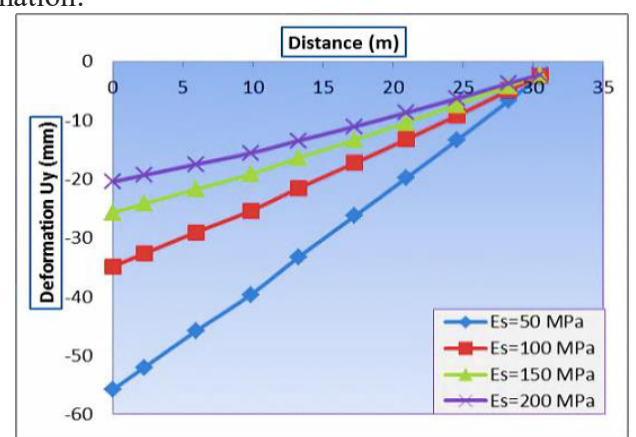

Fig. 14-b. Effect of modulus of elasticity of soil foundation on deformation.

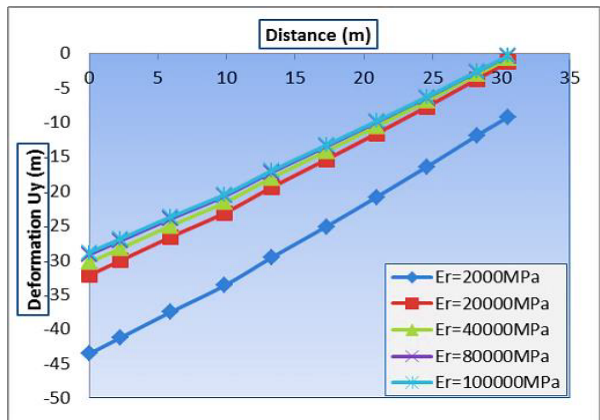

Fig. 14- c. Effect of modulus of elasticity of rock foundation on deformation.

Fig. 14. Effect of modulus of elasticity on deformation; a. barrage body, b. soil foundation, c. rock foundation. c- Poisson's ratio for barrage body $\left(\vartheta_{c}\right)$, soil foundation $\left(\vartheta_{\mathrm{s}}\right)$, and rock foundation $\left(\vartheta_{\mathrm{r}}\right)$; as shown in Figures (15- a, b, and c).

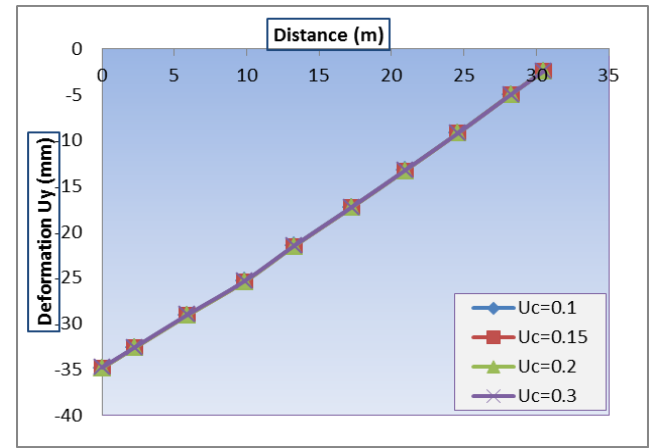

Fig.15-a. Effect of Poisson's ratio of barrage body on deformation.

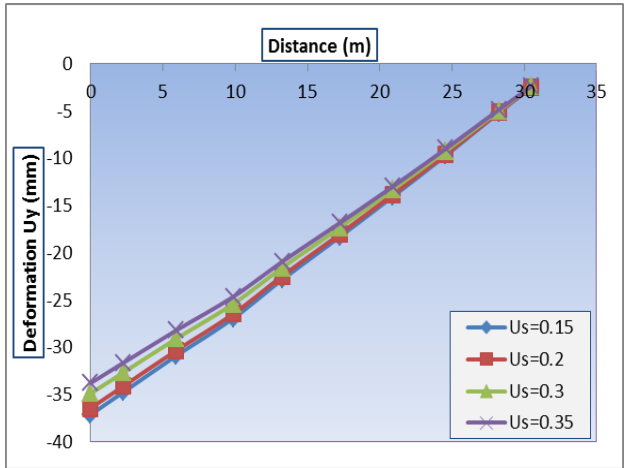

Fig. 15-b. Effect of Poisson's ratio of soil foundation on deformation.

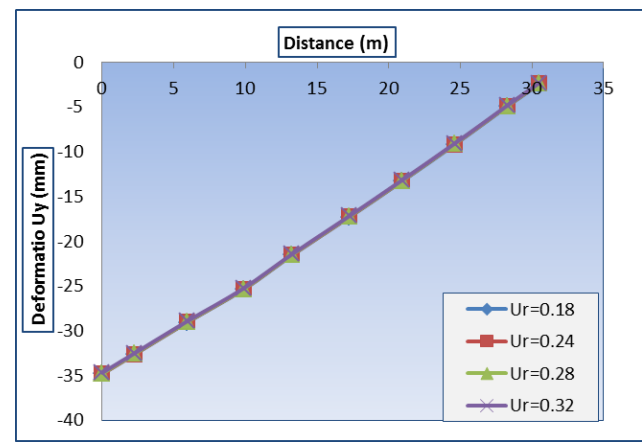

Fig. 15-c. Effect of Poisson's ratio of rock foundation on deformation.

Fig. 15. Effect of Poisson's ratio on deformation; a. barrage body, b. soil foundation, c. rock foundation.

d- Yield stress, $\left(\sigma_{\mathrm{y}}\right)$ for soil and rock foundation as showed in figures (16 - a and $b)$. 


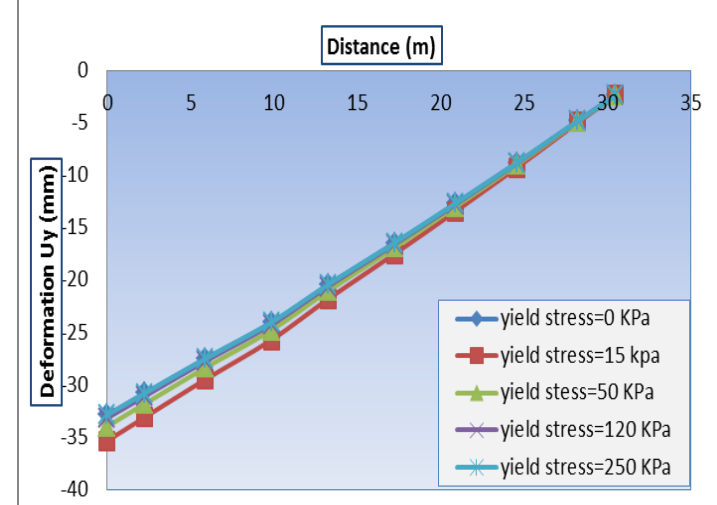

Fig. 16-a. Effect of yield stress of soil foundation on deformation.

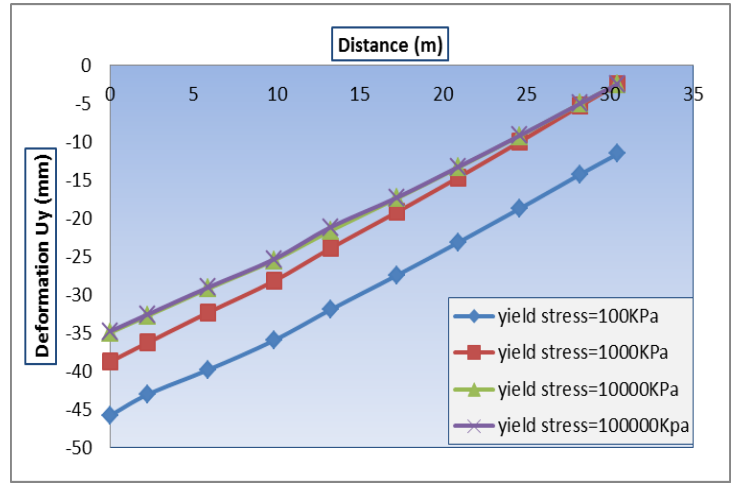

Fig. 16-b. Effect of yield stress of rock foundation on deformation.

Fig.16. Effect of yield stress on deformation; a. soil foundation, b. rock foundation.

It can be noticed from Figs. (13-a, b, and c through $16-a, b$, and c) that the change of parameters may be effect on the deformation of barrage floor rather than others. Figure $(13-$ a) shows that the increasing in density of barrage concrete material $\left(\rho_{c}\right)$ will increase the deformation due to increasing of gravity force, where the increasing both density of soil $\left(\rho_{\mathrm{s}}\right)$, and rock $\left(\rho_{\mathrm{r}}\right)$ foundation material don't effect on the deformation of barrage floor as shown in Figs. (13-b , and c). The most important parameter affected on the deformation is the modulus of elasticity of soil foundation $\left(\mathrm{E}_{\mathrm{s}}\right)$; Fig. (14-a, $\mathrm{b}$, and $\mathrm{c}$ ) according to settlement equation given by [16]:

$$
\mathrm{S}_{\mathrm{e}}=\frac{\mathrm{qBI}}{\mathrm{Eu}}
$$

Where: $\mathrm{q}$ is the applied load per unit area $\left(\mathrm{kN} / \mathrm{m}^{2}\right)$, B is the width of loaded area $(\mathrm{m})$, I is the influence factor which is a function of $\mathrm{H} / \mathrm{B}$ and $\mathrm{L} / \mathrm{B}, \mathrm{H}$ is the depth of layer, $\mathrm{L}$ is the length of structure, and $\mathrm{Eu}$ is young modulus of elasticity $\left(\mathrm{kN} / \mathrm{m}^{2}\right)$. In other hand, Poisson's ratio shows little effects on the deformation of barrage floor as shown in Fig. (15-a, b, and c). Moreover, it is shown from Fig. (16-a and b), that the increasing yield stress of soil foundation material from $(0-250 \mathrm{kPa})$, the deformation will decrease so little, while the increasing yield stress of rock foundation material from (100-
$100000 \mathrm{kPa})$, the deformation will decrease by (28.57\%), where the low value of yield stress of rock make it behave as soft soil.

\subsection{Seepage analysis}

Hassan in his study [17] suggested the different configurations of sheet piles as an effective parameters to find the optimum hydraulic design of barrage. In this study, Four configurations of sheet pile is considered, which is without sheet pile, sheet pile at upstream and downstream, sheet pile at upstream only, and sheet pile at downstream only. The length of sheet pile was $10 \mathrm{~m}$ for upstream and $6 \mathrm{~m}$ for downstream according to limit of length in [17]. The permeability $(\mathbf{K})$ for the selected type of soil (i.e. Gravelly soils) is equal to $(1 \mathrm{~cm} / \mathrm{s})$ according to type of soil foundation [15]. The barrage and foundation sections are simulated for $\mathrm{FL}=8 \mathrm{~m}$ at upstream only for steady seepage condition using PLANE 77 thermal element that available in ANSYS Software to study effects of presence of sheet piles on the uplift pressure, exit hydraulic gradient, and seepage changes. The Geometry of this element is shown in Fig (17).

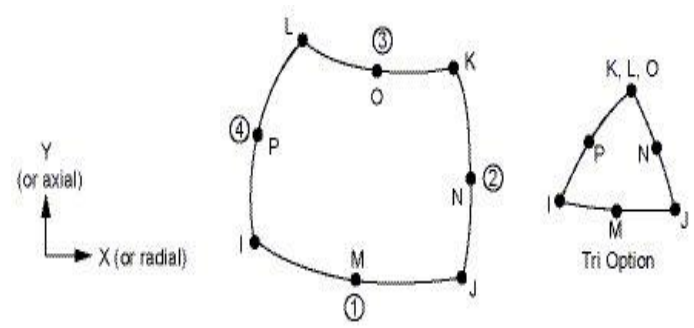

Fig. 17. PLANE 77 element geometry [8].

Figs. (18, 19, 20, and 21) illustrates the results of equipotential lines, flow lines and seepage discharge at foundation underneath barrage floor for given four configurations of sheet piles after the numerical simulation has been run. The maximum seepage flow at exit point downstream barrage floor with up and downstream piles is lesser by $(67.40 \%)$ than without pile. While it is lesser than by $(30.71 \%)$ and $(17.83 \%)$ with upstream pile only and with downstream pile only, respectively and these result are close to the results of [18].The results of seepage could be summarized in Table (5). 


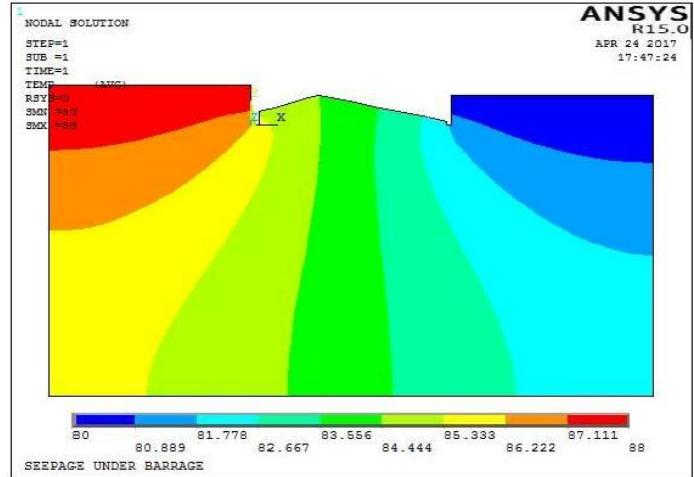

a. Equipotential lines.

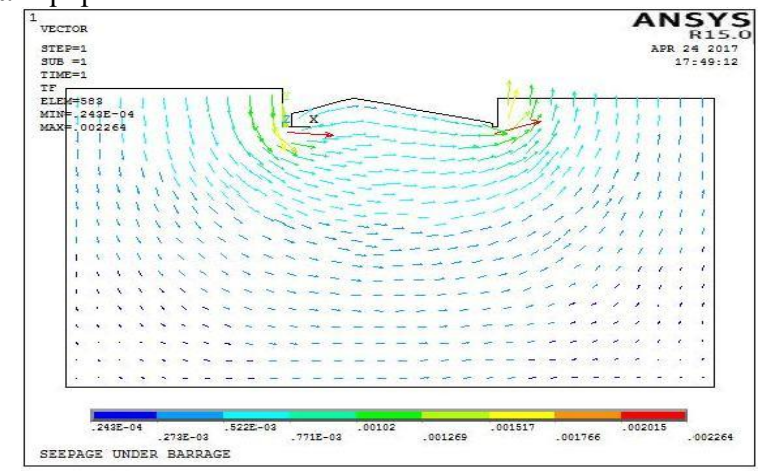

b. Flow lines.

Fig. 18. Cross section of barrage foundation under barrage without sheet pile; a. equipotential lines, b. flow lines.

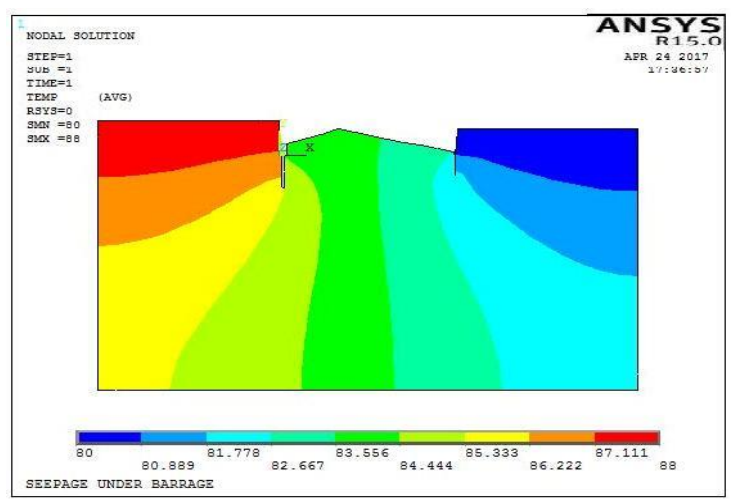

a. Equipotential lines.

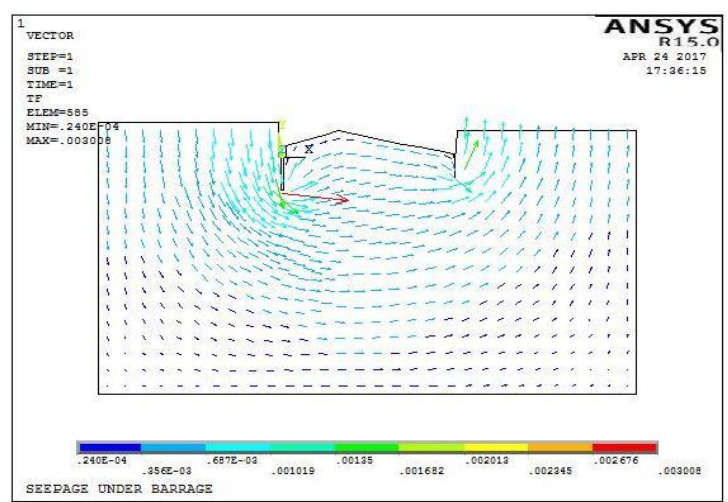

b. Flow lines.

Fig. 19. Cross section of barrage foundation under barrage with sheet pile at upstream and downstream; a. equipotential lines, b. flow lines.

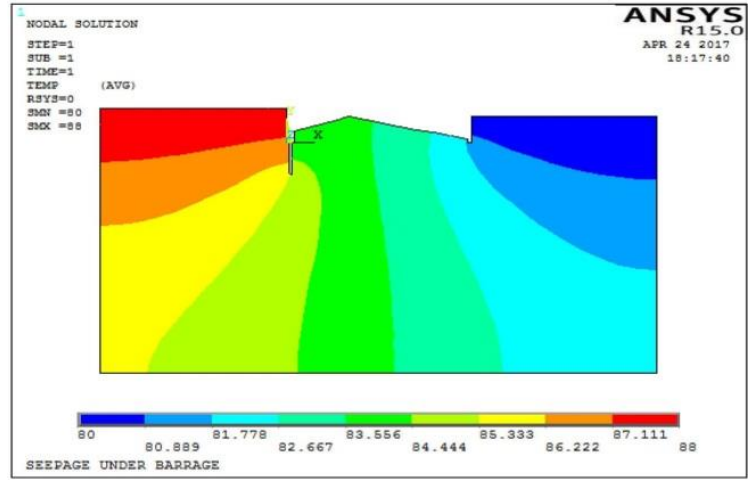

a. Equipotential lines

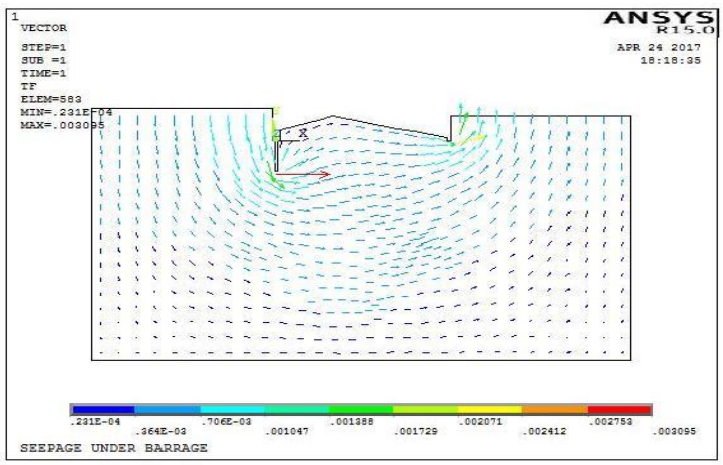

b. Flow lines

Fig. 20. Cross section of barrage foundation under barrage with sheet pile at upstream only; a. equipotential lines, b. flow lines.

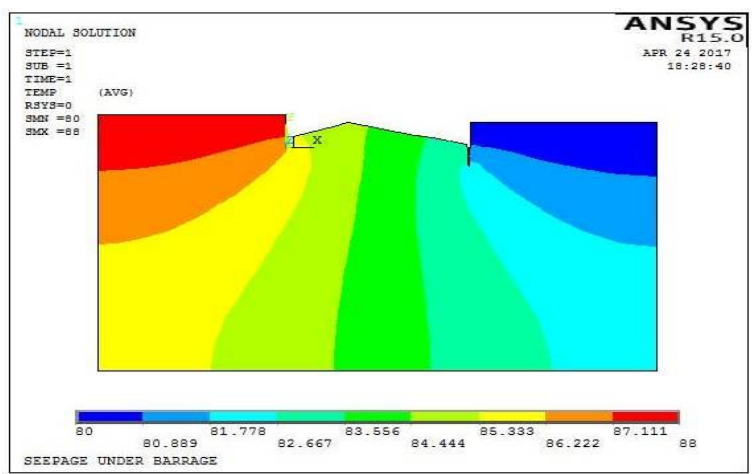

a. Equipotential lines.

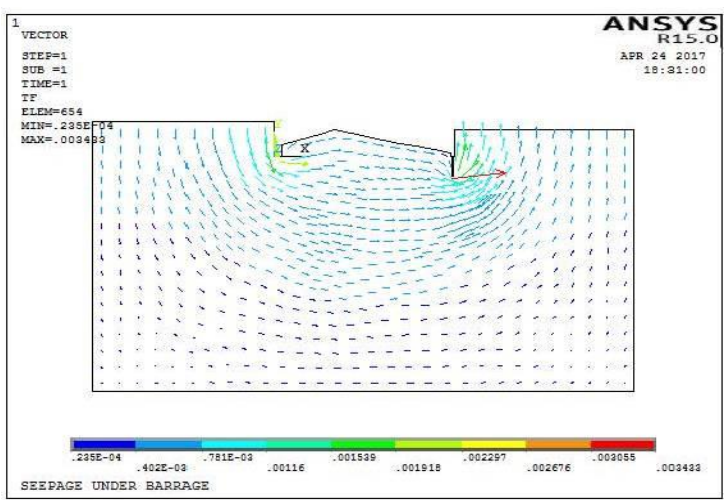

b. Flow lines. 
Fig. 21. Cross section of barrage foundation under barrage with sheet pile at downstream only; a. equipotential lines, b. flow lines.

Table 5. Flow seepage quantity underneath barrage floor condition.

\begin{tabular}{|l|l|}
\hline Barrage floor conditions & $\begin{array}{l}\text { Flow seepage } \\
\left(\mathbf{m}^{2} / \mathbf{s} / \mathbf{m}\right)\end{array}$ \\
\hline Without piles. & $2.264 \times 10^{-3}$ \\
\hline $\begin{array}{l}\text { With both upstream and } \\
\text { downstream piles. }\end{array}$ & $1.350 \times 10^{-3}$ \\
\hline With only upstream pile. & $1.729 \times 10^{-3}$ \\
\hline With only downstream pile. & $1.918 \times 10^{-3}$ \\
\hline
\end{tabular}

The effects of sheet piles on the uplift pressure distribution underneath barrage floor are presented in Fig. 22. It can be noted from this figure that the best condition which give lesser values of uplift pressure only at contact part of barrage floor with foundation is at presence of sheet pile at upstream only.

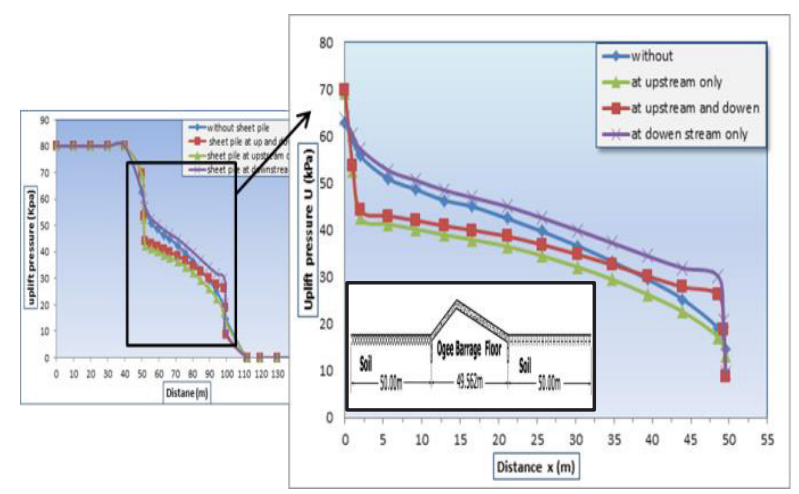

Fig. 22. Uplift pressure distribution in the foundation with different conditions of sheet pile.

The effects of sheet pile presence on the exit hydraulic gradient are presented in Fig. 23. It is shown from this figure that the barrage floor without sheet pile is the critical condition which give results closer to the limit of safe exit gradient $\{$ i.e., $(1 / 6)\}$ [17], while the sheet pile at up and downstream are the most safe condition followed by the pile at downstream only and this is close with results of [18].
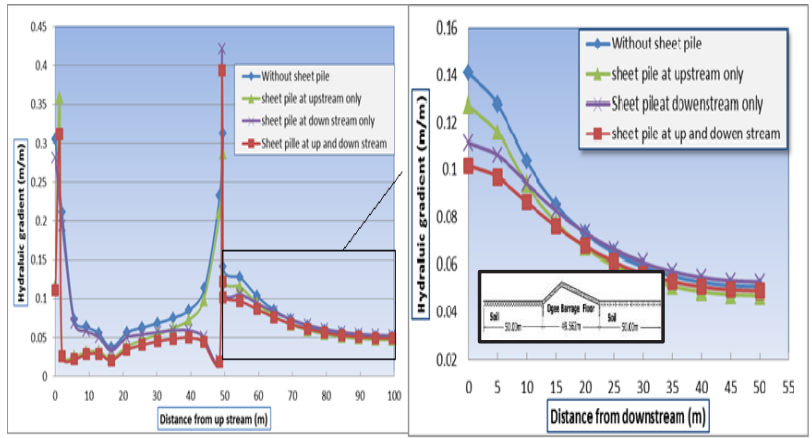

Fig. 23. Effects of the sheet pile existing on the changes of the hydraulic gradient
Moreover, the changes of the seepage discharge underneath barrage and foundation is drawn versus the conditions of the sheet pile is presented in Fig. 24.

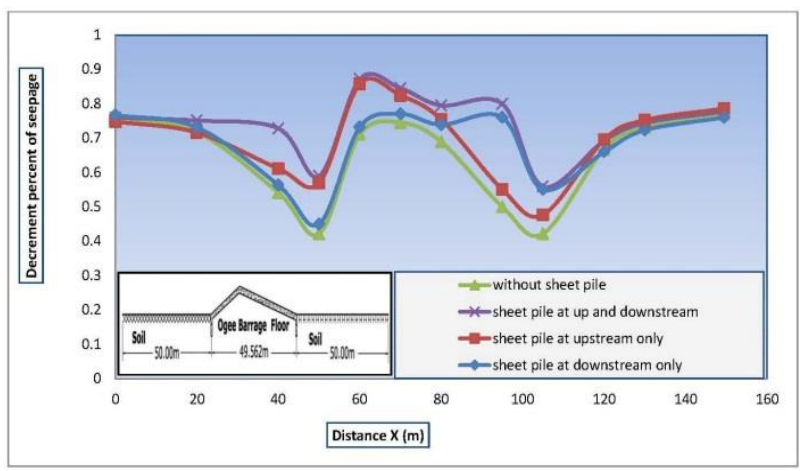

Fig. 24. Effects of the sheet pile existence on the changes of the seepage.

According to Fig. 24, the providing sheet piles at both upstream and downstream give maximum decrement to $(90 \%)$ beneath barrage floor rather than other providing of piles conditions.

\section{Conclusions}

- ANSYS/APDL is adequate tool to simulate and analysis the problem that need sufficient experiences to select suitable available elements to get the acceptable results.

- The deformation in barrage floor has little difference by $(6 \%)$ in linear and non-linear analysis in non-operation case. While this deformation in non-linear analysis in the flow condition is less by $(13 \%)$ than of non-operation case.

- The maximum stress in $y$ - direction is more than that in $\mathrm{x}-$ and $\mathrm{z}-$ - directions due to interaction, where the critical section at rock side of foundation.

- The non-linear deformation of barrage floor is more effective by change of density of barrage concrete itself, modulus of elasticity and yield stress of both soil and rock foundation materials, while no sensitive effect of change of Poisson's ratio on the deformation.

- The maximum seepage flow at exit point downstream barrage floor with upstream and downstream piles is less than that without pile by $(67.40 \%)$. While it is less than that with upstream pile only and with downstream pile only by $(30.71 \%)$ and $(17.83 \%)$, respectively.

- The lesser values of uplift pressure only at contact part of barrage floor with foundation is at presence of sheet pile at upstream only.

- The existence of the sheet pile at both upstream and downstream is an appropriate solution for the hydraulic gradient reduction and piping happening under barrage and reducing the quantity of seepage.

- In the view of stability, the barrage floor is already safe in exist gradient and piping problems with or without piles, where the safe exit hydraulic gradient is far away from the critical limited value with pile at upstream and downstream or with downstream only. 
- The maximum decrement percentage of seepage under barrage floor reach to $(90 \%)$ underneath barrage floor with upstream and downstream pile.

The authors are grateful for the support of staff of AlHindiya Barrage Project for giving opinions that necessarily to finish this study.

\section{References}

1. P. Novak, A. Moffat, C. Nalluri, R. Narayanan, Hydraulic Structures, $4^{\text {th }}$ Edition, Taylor and Francis (2007).

2. A. Mohsin, H. Omran, A.- H. Al-Shukur, IJIRSET, 04, 8961-8973 (2015).

3. A-H. Al-Shukur, A. Al-Rammahi, IJCIET, 08, 873881(2017).

4. A. Al-Qaisi, Optimal Design of Concrete Gravity Dams on Random Soil, PhD. Thesis, Building and Constructing Engineering Department, University of Technology, Baghdad, Iraq (2016).

5. K. Venkatesh, A. Pandey, N. Samadhiya, $15^{\text {th }}$ ICRA GEESD, May 24-29, 45, San Diego, California (2010).

6. Z. Lubkowski, M. Willford, X. Duan, A. Thompson, A. Kammerer, 13 ${ }^{\text {th }}$ WCEE, August 1-6, 1415, Vancouver, B.C., Canada (2004).

7. K. Venkatesh, N. Samadhiya, A. Pandey, $6^{\text {th }}$ ICCH GE, Aug $11^{\text {th }}-$ Aug $16^{\text {th }}$, Missouri University of Science and Technology (2008).

8. ANSYS. ANSYS User's Manual, ANSYS Theory Manual, Version 15.0 ( 2013).

9. American Society for Testing and Materials (ASTM), Annual Book of ASTM Standards, Vol. 04.08 Soil and Rock (I): D421 - D5876, Philadelphia, Pa (2004).

10. Indian Institute of Technology (IIT), Water Resources Engineering, Kharagpur (2008).

11. R. Taylor, P. Beresford, E. Wilson., IJNME, 10 , 1211-1219 (1976).

12. K. Willam, E. Warnke, ISMES, 19, (1975).

13. S. Sypedoor, S. Gholizadeh, S. Talebian, CEES, 27, 295-313(2010).

14. H. Hasan, A. Rahman, H. Ameen, Am. J. Sci. Ind. Res., 03, 94-98 (2012).

15. D. Prices, Engineering Geology: Principles and Practice, deFreitas, Michael (Ed), Chapter 2Geological Materials, 21-61(2009).

16. D. Bergado, S. Ahmed, C. Sampaco, A. Balasubramaniam, GE J., ASCE, 116, $136-155$ (1990)

17.Z. Hassan, Optimal Hydraulic Design of a Barrage Using Genetic Algorithm, M.Sc. Thesis, College of Engineering, University of Babylon (2012).

18. S. Khassaf, A. Al-Adili, R. Rasheed, $13^{\text {th }}$ IWT Conference, Hurghada, Egypt, 301-310 (2009). 